\title{
EVASÃO DA EDUCAÇÃO A DISTÂNCIA: POR QUE OCORRE?
}

\author{
CURITIBA/PR MAIO/2018
}

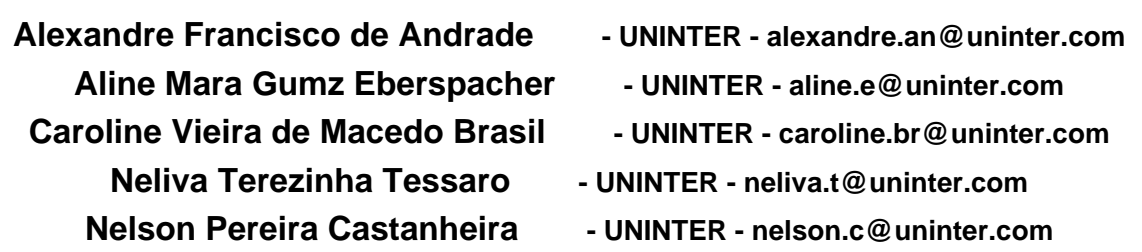

Tipo: Relato de Experiência Inovadora (EI)

Categoria: Pesquisa e Avaliação

Setor Educacional: EDUCAÇÃO SUPERIOR

\begin{abstract}
RESUMO
A evasão escolar é um tema que preocupa tanto os mantenedores das Instituições de Ensino Superior quanto as autoridades governamentais, seja na modalidade presencial, seja na modalidade a distância. Realizou-se uma pesquisa em uma Instituição de Ensino Superior - IES com sede em Curitiba e com polos espalhados em todos os Estados da Federação, onde procurou-se identificar os motivos que levam à evasão, sejam eles de responsabilidade da IES, sejam eles oriundos das condições dos alunos. Foi realizado o contato com uma amostra significativa de alunos evadidos nos cursos superiores tecnológicos e diagnosticado os motivos principais da evasão, sejam eles motivos pessoais do aluno que se evadiu, sejam eles problemas oriundos da IES pesquisada. Identificou-se $o$ perfil que prevalece entre os alunos evadidos, sendo esse do sexo masculino, com faixa etária entre 23 e 30 anos e casado, com filhos. Para que o leitor entenda o cenário da pesquisa, foi relatada a estrutura da instituição pesquisada. A partir dos dados coletados, foi elaborado um plano de ação que visa aumentar a retenção dos alunos e, consequentemente, diminuir os índices de evasão.
\end{abstract}

Palavras-chave: Educação a distância; evasão escolar; retenção dos alunos; cursos superiores 


\section{INTRODUÇÃO}

A presente pesquisa não pretende acabar com a evasão escolar, nem apresentar um modelo que seja a solução para resolver esse grande problema na educação superior brasileira, seja na área pública, seja na área privada, seja no ensino presencial, seja no ensino a distância.

A pesquisa concentrou-se numa amostra significativa de alunos evadidos nos cursos superiores tecnológicos de uma Instituição de Ensino Superior - IES com sede em Curitiba e com polos em todos os Estados da Federação, na modalidade a distância. Foram contatados mais de dois mil alunos que se evadiram durante os anos de $2016 \mathrm{e}$ 2017, escolhidos aleatoriamente, dos quais 822 responderam as perguntas feitas pelos autores desta pesquisa, que visaram identificar o perfil social do aluno evadido e as causas da evasão. Não foram considerados os alunos que foram reprovados, mas somente aqueles que, por algum motivo, abandonaram o curso.

A pergunta da qual se partiu na presente pesquisa foi "O que leva um aluno de ensino superior a desistir de continuar os seus estudos?". Procurou-se identificar o que motivou esses alunos a se afastarem da sala de aula, considerando que um curso superior tecnológico tem, em média, apenas dois anos de duração.

\section{A EVASÃO}

A evasão pode ser definida de várias maneiras. Gaioso (2005) a define como sendo a interrupção no ciclo de estudos, em qualquer nível de ensino.

A evasão no ensino superior é um problema complexo pois envolve muitas várias, nem todas controláveis. Para Coelho (2005), a evasão pode ter como origem:

a) a falta da presença docente, pois acredita-se que na relação face-a-face entre professores e alunos há maior interação no processo educacional;

b) a inabilidade dos alunos em lidar com novas tecnologias;

c) a ausência de reciprocidade na comunicação, ou seja, falta de interatividade entre alunos e professores; 
d) o aluno não se sente parte da Instituição de ensino, por não haver o contato permanente com outros alunos.

Silva Filho et al (2007, p. 659) afirmam que "há necessidade de realizar estudos sistemáticos com vistas a reduzir as taxas de evasão e evitar os desperdícios, tanto do ponto doe vista social quanto do financeiro". E para o aluno não evadir, a Instituição deverá se preocupar, antes, com a retenção desse aluno. Nesse aspecto, Workman e Stenard (1996) dizem que há a necessidade de prestar atenção em algumas necessidades do aluno que influenciarão na sua necessidade de permanecer ou não num curso a distância:

a) consistência e clareza dos objetivos, das políticas e dos procedimentos relacionados ao curso;

b) automotivação;

c) identificar-se com a escola e com os colegas de turma, ou seja, está relacionada ao senso de comunidade e ao compromisso institucional que [10] se refere;

d) integração social;

e) infraestrutura e suporte institucional.

Uma pesquisa sobre evasão em cursos superiores tecnológicos foi realizada em 2009 por Scali, em uma IES pública do Estado de São Paulo. Ele diagnosticou que as principais causas da evasão foram:

a) definição de curso de ingresso;

b) localização da instituição;

c) formação e atuação profissional do tecnólogo;

d) condições relacionadas ao trabalho e condições financeiras.

Pretendeu-se, quase uma década depois, fazer uma pesquisa semelhante, em uma Instituição privada, e comparar os resultados das mesmas. Ambas as pesquisas focaram nos alunos evadidos de cursos superiores tecnológicos. 


\section{A ESTRUTURA DE EAD DA INSTITUIÇÃO PESQUISADA}

É importante posicionar o leitor quanto ao ambiente da pesquisa, ou seja, como é operacionalizado o ensino a distância na Instituição pesquisada. A Instituição tem mais de 600 polos de apoio presencial - PAP espalhados em todo o território nacional, cobrindo os 26 Estados e o Distrito federal. Em cada PAP há, além do gestor do polo, um coordenador de polo e tutores locais para o apoio aos alunos do mesmo. Cada disciplina dos cursos superiores tecnológicos tem um livro escrito com linguagem dialógica e os alunos recebem, gratuitamente, todos os livros do seu curso. Todas as aulas são gravadas e disponibilizadas no Ambiente Virtual de Aprendizagem - AVA para tantos acessos quantos o aluno desejar. Há uma biblioteca virtual com milhares de títulos para o aluno acessar quando quiser. Na sede da Instituição há tutores disponíveis para sanar as dúvidas de cem por cento dos conteúdos ministrados. Toda disciplina tem duas aulas interativas e os alunos entram em contato com o professor via chat, onde um mediador informa as dúvidas dos mesmos.

Todo PAP traça diretrizes que permitam o desenho de um projeto global de orientação e que proporcione as condições de infraestrutura e organização necessárias ao seu bom desenvolvimento. (POLAK, 2000).

\section{METODOLOGIA DA PESQUISA}

Quanto à natureza, foi uma pesquisa aplicada, que considera investigar as causas da evasão dos alunos de cursos superiores tecnológicos. Quanto ao propósito, foi uma pesquisa exploratório-descritiva, pois, conforme Silva e Menezes (2001), a pesquisa exploratória visa proporcionar maior familiaridade com o problema com vistas a torná-lo explícito. Quanto ao procedimento técnico, os dados foram coletados a partir de um roteiro de entrevista que apresentou informações dos respondentes para tratamento estatístico das questões. Utilizou-se um instrumento de entrevista semiestruturada com perguntas de cunho pessoal que permitiram identificar o perfil do aluno evadido, além das perguntas abertas que permitiram diagnosticar os motivos da evasão. Para Manzini (1990/1991, p. 54), a entrevista semiestruturada está focalizada em um assunto sobre o qual confeccionamos um roteiro com perguntas principais, complementadas por outras questões inerentes às circunstâncias momentâneas à entrevista. $\mathrm{O}$ aluno contatado pode dar uma ou mais razões para a sua evasão, o que nos permitiu uma análise não só 
qualitativa, mas também quantitativa das principais causas identificadas.

\section{OS DADOS COLETADOS}

Ao analisar o perfil do aluno que se evadiu, observou-se que prevalece o aluno do sexo masculino, com faixa etária entre 23 e 30 anos e casado, com filhos.

Procurou-se identificar, junto aos 822 respondentes, se a evasão ocorreu por motivos de ordem pessoal ou se foi por motivos oriundos da Instituição de Ensino, ao que se diagnosticou que:

a) $70,44 \%$ dos alunos evadidos alegaram motivos de ordem pessoal;

b) $23,96 \%$ dos alunos evadidos alegaram motivos relacionados à Instituição de Ensino;

c) os demais $5,60 \%$ dos alunos evadidos não pontuaram o motivo da evasão.

Os principais motivos alegados por aqueles respondentes que alegaram motivo de ordem pessoal, por ordem de importância, foram:

a) desemprego no decorrer do curso;

b) perda de rendimento, o que tornou a mensalidade incompatível com o mesmo;

c) desestruturação familiar no decorrer do curso;

d) falta de tempo para a realização de todas as atividades solicitadas, pois achava que por ser a distância precisaria estudar menos;

e) repetência em disciplinas;

f) dificuldade no uso da Internet e demais ferramentas tecnológicas;

g) desinteresse pelo curso;

h) mudaram para outra instituição de ensino superior. 
Os principais motivos alegados por aqueles que se evadiram por problemas oriundos da Instituição de Ensino, por ordem de importância, foram:
a) mal atendimento na tutoria local;
b) não se adaptaram à metodologia a distância;
c) não gostaram do conteúdo do curso;
d) currículos distantes das necessidades;
e) formas de avaliação das disciplinas.

\section{AÇÕES PARA AUMENTAR A RETENÇÃO}

Tão importante quanto a captação de alunos, é a retenção dos mesmos para, posteriormente, fidelizá-los. O cenário econômico no Brasil, nos últimos dois anos, tem contribuído sobremaneira para o aumento da evasão no ensino superior e para a diminuição nas matrículas de novos alunos, principalmente nos cursos superiores tecnológicos, nosso objeto de pesquisa. Esse cenário não reflete somente um problema social, mas também um problema institucional, pois abala a imagem da Instituição de Ensino Superior quando os alunos abandonam o curso. (DESJARDINS; AHLBURG; MC'CALL, 1999).

Alunos sempre evadiram das IES. Até mesmo no auge do crescimento do ensino superior brasileiro este problema existia. Clientes "Desistem", "Cancelam e Trancam Matrículas" e "Transferem-se", e geralmente isto ocorre depois de se tornarem inadimplentes ou, antes, com seus compromissos ainda honrados. (ABMES, 2014).

Que ações devem ser adotadas para a retenção dos alunos? A partir dos dados coletados na pesquisa, sugere-se;

a) adotar preços diferenciados por localidade, tendo em vista a grande heterogeneidade do território brasileiro quanto à variável renda;

b) ter planos de financiamento alternativos para negociação com alunos inadimplentes, para custeio dos alunos; 
c) treinar continuadamente os tutores dos polos de apoio de presencial - PAPs;

d) manter comunicação com os alunos permanentemente, via tutoria, por e-mail, por telefone, por mensagem no celular, enviando pop ups e quaisquer outros meios de comunicação disponíveis na Instituição de Ensino;

e) manter as aulas e demais materiais de apoio sempre atualizados;

f) ofertar aulas de reforço e de nivelamento para todos os alunos, no Ambiente Virtual de Aprendizagem - AVA da Instituição;

g) manter no quadro docente os melhores professores de cada área;

h) manter o quadro de tutores com excelentes professores que possam sanar rapidamente as dúvidas dos alunos;

i) os PAPs deverão ter excelente biblioteca e laboratório com fácil acesso à Internet;

j) os projetos pedagógicos dos cursos deverão ser permanentemente atualizados em função das necessidades do mercado;

k) os instrumentos de avaliação deverão ser de fácil acesso, fácil compreensão por parte dos alunos e os resultados deverão divulgados tão logo os alunos terminem o processo avaliativo;

I) o AVA deve ser de fácil utilização (comunicação amigável) e rico em conteúdos;

m) manter contato com as empresas que receberão os egressos de cada curso para manter os conteúdos ministrados coerentes com as necessidades do mercado de trabalho.

\section{CONCLUSÃO}

Os fatores identificados na pesquisa, causadores da evasão nos cursos superiores tecnológicos, mostraram primeiramente que o aluno, hoje, está mais maduro e mais atento ao que o mercado de trabalho espera dele. Chamou a atenção a faixa etária dos alunos evadidos, concentrada entre 23 e 30 anos de idade. 
Ao comparar os resultados encontrados na presente pesquisa com a anteriormente realizada em 2009, observa-se que, apesar do tempo que separa os dois eventos, os motivos que levam um aluno a desistir de concluir um curso superior já iniciado não se alteraram significativamente. São problemas de ordem socioeconômica, principalmente relacionados à renda, e problemas que demonstram a dificuldade que um aluno encontra ao se matricular, pela primeira vez, em um curso na modalidade a distância. Nesse caso, problemas de administração do seu próprio tempo, problemas de acesso e de interação com as ferramentas tecnológicas e falta de se identificar com o curso escolhido.

Uma vez identificados os principais fatores de evasão, propôs-se um conjunto de ações que a Instituição de ensino Superior deve adotar para aumentar a retenção do aluno e, consequentemente, diminuir os índices de evasão.

Observou-se, também, que a evasão não tem sua origem somente no aluno mas também na própria Instituição de Ensino, ao não observar atentamente o que pede o mercado de trabalho, as expectativas dos alunos, a permanente atualização do seu corpo docente aí incluídos os tutores e a atualização dos projetos pedagógicos dos cursos.

As ferramentas de interface com os alunos precisam ter um olhar especial por parte do marketing, da coordenação do curso, dos professores e dos tutores. A comunicação com os alunos deve ter igual atenção por parte dos protagonistas que estão física e geograficamente distantes da instituição, mas próximos aos alunos, ou seja, aqueles que atuam nos polos de apoio presencial.

\section{REFERÊNCIAS}

ABMES. Gestão da retenção de alunos em instituições de educação superior. Disponível em: . Acesso em: 1 maio 2018.

COELHO, M. L. A evasão nos cursos de formação continuada de professores universitários na modalidade de educação a distância via Internet. Universidade Federal de Minas Gerais, 2002.

DESJARDINS, Stephen; AHLBURG, D.; MC'CALL, B. An event history model of student departure. Economics of Education Review, 1999. 
GAIOSO, Natalicia Pacheco de Lacerda. O fenômeno da evasão escolar na educação superior no Brasil. 2005. 75 f. Dissertação (Mestrado em Educação) - Programa de Pós-Graduação em Educação da Universidade Católica de Brasília, Brasília, 2005.

MANZINI, E. J. A entrevista na pesquisa social. Didática, São Paulo, v. 26/27, p. 149-158, 1990/1991.

POLAK, Ymiracy N. S. Iniciando o percurso em EAD na UFPR. In: POLAK, Ymiracy N. S.; MARTINS, Onilza B.; SÁ, Ricardo Antunes de. Educação a distância: um debate multidisciplinar. Curitiba: UFPR/PROGRAD/NEAD, 2000.

SCALI, Danyelle Freitas. A evasão nos cursos superiores de tecnologia: a percepção dos estudantes sobre seus determinantes. 164p. Dissertação (Mestrado em Educação). Campinas-SP: Unicamp, 2009.

SILVA, E. L.; MENEZES, E. M. Metodologia da pesquisa e elaboração de dissertação. 3. ed. Florianópolis: Laboratório de Ensino a Distância da UFSC, 2001.

SILVA FILHO, Roberto Leal Lobo et al. A evasão no ensino superior brasileiro. Cadernos de Pesquisa, São Paulo, v.37, n.132, p.641-659, 2007.

WORKMAN, J. J.; STENARD, R. A. (1996). Student support services for distance learners. DEOSNEWS, 6(3), 1996. Distance Education Online Symposium Website. Disponível em: <http://www.ed.psu.edu/csde/deos/deosnews/deosnews6_3.asp>. Acesso em: 11 maio 2018. 